Article

\title{
Analysis of Physical Activity and Comorbidities in Spanish Asthmatics
}

\author{
Sheila Sánchez Castillo ${ }^{1, * \mathbb{C}}$, Lee Smith ${ }^{2, *}$, Arturo Díaz Suárez ${ }^{1}$ and \\ Guillermo Felipe López Sánchez ${ }^{1, *(\mathbb{D})}$ \\ 1 Faculty of Sport Sciences, University of Murcia, 30720 San Javier (Murcia), Spain; ardiaz@um.es \\ 2 The Cambridge Centre for Sport and Exercise Sciences, Anglia Ruskin University, Cambridge CB5 8DZ, UK \\ * Correspondence: sheila.sanchez1@um.es (S.S.C.); lee.smith@anglia.ac.uk (L.S.); gfls@um.es (G.F.L.S.)
}

Received: 21 May 2020; Accepted: 26 June 2020; Published: 29 June 2020

check for updates

\begin{abstract}
The prevalence of comorbidities in asthmatics is high. Comorbidities may complicate the clinical management of asthma, increasing the risk for exacerbation and even death. The objective of the present research was to establish the prevalence of $31 \mathrm{asthma}$ comorbidities and to assess the association of these comorbidities with physical activity (PA) in Spanish asthmatics. Data of the Spanish National Health Survey 2017 (cross-sectional design) were used in this study. A total of 1014 people (42.1\% males) with asthma participated in this study (age range 15-69 years). The IPAQ (International Physical Activity Questionnaire) short form was the instrument administered to evaluate PA (exposure), and the self-reported answer to the question "Have you ever been diagnosed with ... ?" determined the presence of comorbidities (outcomes). This association was assessed by multivariable logistic regression. Results demonstrated a huge presence of comorbidities (89.3\%). The most prevalent were chronic allergy (61.1\%), chronic lumbar pain (28.7\%), chronic cervical pain $(24.2 \%)$, high cholesterol (20.9\%), Chronic Obstructive Pulmonary Disease (COPD) (19.4\%), migraine (19.2\%) and hypertension (19.3\%). PA level under 600 metabolic equivalent of task (MET)-min/week showed a significant association with urinary incontinence (3.10 [1.62-5.94]), osteoporosis (1.90 [1.00-3.61]) and chronic anxiety (1.69 [1.13-2.53]). Therefore, comorbidities and PA levels should be considered in the prevention and treatment of asthmatics, in order to improve their quality of life.
\end{abstract}

Keywords: respiratory health; exercise; prevalence; adults

\section{Introduction}

Asthma is a frequent and potentially serious chronic condition that affects all age groups [1]. Over 339 million people worldwide are affected by asthma [2]. According to previous research, the worldwide prevalence of asthma diagnosed in the adult population is $4.3 \%$ [3]. In Spain, the epidemiological study of chronic obstructive pulmonary disease (IBERPOC) found a prevalence of $4.9 \%$ in adults aged 40-69 years [4], and according to the Spanish National Survey 2017, a prevalence of $6 \%$ was found in Spanish people aged 15-69 years [5].

Chronic airway inflammation related to wheezing, chest tightness, shortness of breath, cough and variability in expiratory airflow limitation are some of the symptoms present in asthmatics. An insufficient control of asthma symptoms is a risk factor to develop crisis relating to asthma [1]. The previous aspects, together with the possibility of having EIB (exercise-induced bronchoconstriction), could reduce physical activity (PA) levels in asthmatics [6]. Therefore, asthmatics are usually involved in lower levels of PA in comparison with non-asthmatics [6,7]. In people with asthma, regular PA may be useful in the control of asthma [8-10]. Several studies suggest that regular PA reduces asthma symptoms [11,12], airway responsiveness [13], EIB [9] and the risk of asthma exacerbations [13,14] and increases exercise capacity $[15,16]$ and quality of life $[9,11,13]$ in people with asthma. 
However, asthma is a heterogeneous disease that can be associated with a number of comorbidities. The term comorbidity was coined in 1970 by Feinstein and it refers to "any additional co-existing ailment" [17]. Comorbidities could be independent of asthma or be associated with the disease, but they could complicate clinical management of asthma [18,19], increasing the risk for exacerbation [20], unscheduled asthma care [21], poor asthma control and impaired quality of life [1] and mortality [22]. Therefore, it is important to recognize them.

Rhinosinusitis, food allergy, obstructive sleep apnoea syndrome (OSAS), gastroesophageal reflux (GER) and mental health disorders are the most frequent conditions in people with asthma $[1,18,19,23]$. Asthmatics have significantly more comorbid conditions than non-asthmatics [24,25]. A recent study, which examined the prevalence of 39 comorbidities in more than one million Scottish adults, found that the most prevalent comorbidities in adults with asthma were hypertension (20\%), depression $(17 \%)$, pain $(16 \%)$ and COPD (chronic obstructive pulmonary disease) $(13 \%)$ [26]. Moreover, obese patients show more difficulties in the control of asthma, probably because of a different type of airway inflammation that contributes to other comorbidities like OSAS and GER and due to a poor shape and a decrease in lung volume caused by abdominal fat, which contributes to dyspnoea [1].

It is known that sustained and regular participation in PA helps not only in primary, but also in secondary prevention of a series of chronic conditions [27-29]. However, there is no evidence about how PA can contribute to reduce the risk of suffering from comorbidities in asthmatic adults. It is hypothesized that lower PA levels would increase the risk of comorbidities.

Knowledge about the spectrum of diseases that could affect asthmatics and about how they differ according to PA levels would aid health professionals to identify, prioritize and control asthma comorbidities. Hence, the purpose of this research was to establish the prevalence of 31 different asthma comorbidities and to analyse the associations of levels of PA with the risk of these comorbidities in Spanish people with asthma aged 15-69 years.

\section{Materials and Methods}

\subsection{Study Design}

This research had a cross-sectional design, and it was written following the STROBE guidelines (Strengthening the Reporting of Observational Studies in Epidemiology) [30].

\subsection{The Survey}

We analysed data extracted from the 2017 Spanish National Health Survey. All details about the survey method were previously published [31]. In summary, a stratified three-stage sampling was utilized for data collection. Firstly, the census categories were contemplated, then the family dwellings, and finally, a family member aged 15 or over was elected within each dwelling. The sections were selected within each stratum with probability proportional to their size. A systematic sampling was used to choose the dwellings with equal probability in each section, prior arrangement by size of the dwelling. This procedure led to self-weighting samples in each stratum. To select the family member who filled out the Adult Questionnaire., the random Kish method was employed, which assigns equal probability to all adults in the dwelling. Data were collected by a CAPI (computer-assisted personal interviewing), carried out in the selected participants' dwellings. The interviewers, who were previously qualified, filled in the questionnaires with the information provided by the participants. This research was executed following the principles of the World Medical Association Declaration of Helsinki. Data from the Spanish National Health Survey are public and anonymous, so no ethical approval was required [31]. The present secondary analyses were approved by the Ethical Research Committee of the University of Murcia. 


\subsection{Participants}

The participants of this study were Spanish people suffering from asthma $(n=1014 ; 587$ females and 427 males) (Table 1). Inclusion criteria were: (1) age range 15-69 years and (2) affirmative answer to the question "Have you ever been diagnosed with asthma?" People older than 69 years were not taken into account since they did not respond to the PA questions of the survey. The International Physical Activity Questionnaire (IPAQ) short form was firstly designed for supervising PA in adults (age range 15-69 years). Then, until further development and testing is carried out, the use of IPAQ is not advisable in younger and older ages [32]. Before responding to the survey questions, all participants voluntarily agreed to participate in the study by signing an informed consent form.

Table 1. Sample characteristics according to physical activity (PA) level.

\begin{tabular}{|c|c|c|c|c|c|c|c|}
\hline \multirow[b]{2}{*}{ Characteristic } & \multirow[b]{2}{*}{ Category } & \multirow[b]{2}{*}{$\mathbf{N}$} & \multicolumn{2}{|c|}{$\mathrm{PA}<600 \mathrm{MET} \cdot \mathrm{min} /$ Week } & \multicolumn{2}{|c|}{$\mathrm{PA} \geq 600 \mathrm{MET} \cdot \mathrm{min} /$ Week } & \multirow[b]{2}{*}{$p$} \\
\hline & & & $\mathbf{N}$ & $\%$ & $\mathbf{N}$ & $\%$ & \\
\hline \multirow[t]{2}{*}{ Sex } & Male & 427 & 122 & 28.6 & 305 & 71.4 & \multirow[b]{2}{*}{0.081} \\
\hline & Female & 587 & 198 & 33.7 & 389 & 66.3 & \\
\hline \multirow[t]{3}{*}{ Education } & Level A & 466 & 171 & 36.7 & 295 & 63.3 & \multirow{3}{*}{$0.003 *$} \\
\hline & Level B & 195 & 59 & 30.3 & 136 & 69.7 & \\
\hline & Level C & 353 & 90 & 25.5 & 263 & 74.5 & \\
\hline \multirow[t]{2}{*}{ Marital Status } & Married & 509 & 182 & 35.8 & 327 & 64.2 & \multirow{2}{*}{$0.004^{*}$} \\
\hline & Not Married & 505 & 138 & 27.3 & 367 & 72.7 & \\
\hline \multirow[t]{3}{*}{ Smoking } & Current & 235 & 79 & 33.6 & 156 & 66.4 & \multirow{3}{*}{0.254} \\
\hline & Former & 265 & 73 & 27.5 & 192 & 72.5 & \\
\hline & Never & 514 & 168 & 32.7 & 346 & 67.3 & \\
\hline \multirow{2}{*}{ Alcohol } & Yes & 692 & 199 & 28.8 & 493 & 71.2 & \multirow[b]{2}{*}{$0.005^{*}$} \\
\hline & No & 322 & 121 & 37.6 & 201 & 62.4 & \\
\hline \multirow[t]{3}{*}{ Obesity } & Yes $(\geq 30)$ & 220 & 96 & 43.6 & 124 & 56.4 & \multirow{3}{*}{$<0.001 *$} \\
\hline & No & 772 & 214 & 27.7 & 558 & 72.3 & \\
\hline & Missing & 22 & 10 & & 12 & & \\
\hline \multirow[t]{2}{*}{ Comorbidities } & Yes & 905 & 292 & 32.3 & 613 & 67.7 & \multirow[b]{2}{*}{0.163} \\
\hline & No & 109 & 28 & 25.7 & 81 & 74.3 & \\
\hline \multirow[t]{3}{*}{ Medication } & Yes & 822 & 259 & 31.5 & 563 & 68.5 & \multirow{2}{*}{0.944} \\
\hline & No & 192 & 61 & 31.8 & 131 & 68.2 & \\
\hline & & & Av. & SD & Av. & SD & \\
\hline BMI & & & 27.3 & 5.9 & 25.9 & 5.0 & $<0.001$ * \\
\hline Age & & & 45.2 & 14.4 & 42.2 & 14.8 & $0.003 *$ \\
\hline
\end{tabular}

N: sample size; \%: percentage; MET: Metabolic equivalent of task; Level A: $\leq 1$ st period secondary; Level B: 2nd period secondary and post-secondary (not tertiary); Level C: tertiary; Av.: average; SD: standard deviation. $p$-values are based on chi-squared tests (categorical) and T tests (continuous). ${ }^{*} p<0.05$.

\subsection{Physical Activity (Exposure)}

PA was evaluated with the IPAQ short form. Total PA metabolic equivalent of task (MET)minutes/week was calculated by the following formula: sum of walking + moderate + vigorous MET.minutes/week scores. Then, following the instructions for data processing and analysis of the IPAQ, participants were divided in two groups [32]: (1) under $600 \mathrm{MET} \cdot \mathrm{minutes} /$ week and (2) at least $600 \mathrm{MET} \cdot \mathrm{minutes} /$ week, which meant achieving PA recommendations. IPAQ has been validated in adult populations worldwide, and it is a valid ( $\rho=0.30,95 \%$ CI: $0.23-0.36)$ and reliable (Spearman's $\rho=0.81,95 \%$ CI: 0.79-0.82) instrument [33]. The IPAQ short form has been validated in Spanish adults as well $(\mathrm{r}=0.277 ; p<0.05)$ with a $75 \%$ of sensitivity and specificity $(\mathrm{k}=0.33)$ [34].

\subsection{Comorbidities (Outcomes)}

The 31 comorbidities analysed were based on the data available in the 2017 Spanish National Health Survey. Participants who answered affirmatively to the question "Have you ever been 
diagnosed with ... (each comorbidity studied)"? were determined to suffer from that specific condition. The comorbidities studied are described in Table 2. Chronic allergy includes rhinitis, conjunctivitis, dermatitis, food allergy or another kind of allergy (excluding allergic asthma). Some of these diseases were analysed in previous studies, and rhinosinusitis, food allergy, gastroesophageal reflux (GER), psychological diseases and obstructive sleep apnoea syndrome (OSAS) were found to be common in asthma patients $[1,23]$.

Table 2. Prevalence of comorbidities in people with asthma.

\begin{tabular}{|c|c|c|c|c|}
\hline Group of Comorbidities & Comorbidities & $\mathbf{N}$ & $\%$ & Global \% \\
\hline \multirow{6}{*}{ Cardiovascular diseases } & Hypertension & 196 & 19.3 & \multirow{6}{*}{32.2} \\
\hline & Myocardial infarction & 14 & 1.4 & \\
\hline & Angina, coronary HD & 20 & 2.0 & \\
\hline & Other HD & 50 & 4.9 & \\
\hline & Stroke & 16 & 1.6 & \\
\hline & Varicose veins (legs) & 143 & 14.1 & \\
\hline \multirow{4}{*}{ Musculoskeletal disorders } & Arthrosis & 187 & 18.4 & \multirow{4}{*}{39.3} \\
\hline & CBP cervical & 245 & 24.2 & \\
\hline & CBP lumbar & 291 & 28.7 & \\
\hline & Osteoporosis & 49 & 4.8 & \\
\hline Immunological disease & Chronic allergy & 625 & 61.6 & 61.1 \\
\hline Respiratory disease & COPD & 197 & 19.4 & 19.4 \\
\hline \multirow{4}{*}{ Digestive problems } & Liver dysfunction & 19 & 1.9 & \multirow{4}{*}{18.1} \\
\hline & Stomach/duodenal ulcer & 55 & 5.4 & \\
\hline & Chronic constipation & 64 & 6.3 & \\
\hline & Haemorrhoids & 118 & 11.6 & \\
\hline \multirow{4}{*}{ Urogenital diseases } & Urinary incontinence & 51 & 5.0 & \multirow{4}{*}{15.5} \\
\hline & Kidney problems & 56 & 5.5 & \\
\hline & Prostate problems (men) & 27 & 6.3 & \\
\hline & Menopausal problems (women) & 57 & 9.7 & \\
\hline Eye problems & Cataracts & 58 & 5.7 & 5.7 \\
\hline Dermatological problems & Chronic skin problems & 118 & 11.6 & 11.6 \\
\hline \multirow{3}{*}{ Mental health problems } & Depression & 152 & 15.0 & \multirow{3}{*}{20.6} \\
\hline & Chronic anxiety & 143 & 14.1 & \\
\hline & Other mental problems & 28 & 2.8 & \\
\hline Neurological disorder & Migraine & 195 & 19.2 & 19.2 \\
\hline Neoplasias & Malignant tumours & 51 & 5.0 & 5.0 \\
\hline \multirow{3}{*}{ Endocrinal and metabolic diseases } & Thyroid problems & 83 & 8.2 & \multirow{3}{*}{27.3} \\
\hline & Diabetes & 73 & 7.2 & \\
\hline & High cholesterol & 212 & 20.9 & \\
\hline Permanent inj & s (accident) & 92 & 9.1 & 9.1 \\
\hline
\end{tabular}

$\mathrm{N}$ : sample size; \%: percentage, HD: heart disease, CBP: chronic back pain, COPD: chronic obstructive pulmonary disease.

Comorbidities were classified following the ICD (International Classification of Diseases) in 13 different groups: (1) cardiovascular diseases; (2) musculoskeletal disorders; (3) immunological diseases; (4) respiratory diseases; (5) digestive problems; (6) urogenital diseases; (7) eye problems; (8) dermatological problems; (9) mental health problems; (10) neurological disorders; (11) neoplasias; (12) endocrinal and metabolic diseases; (13) permanent injuries [35].

\subsection{Covariates}

Covariates were selected according to previous research [36,37]. Sex, age, education level and marital status were included as sociodemographic variables. Education level was based on the highest level completed and was categorized according to the Spanish Classification of Education Levels as Level A ( $\leq 1$ st period secondary), Level B (2nd period secondary and post-secondary (not tertiary)), and Level C (tertiary) [38]. Marital status was classified as married versus not married, which included 
those who were single, divorced, separated or widowed. Smoking, alcohol consumption and BMI (body mass index) were also selected as covariates. Smoking was categorised into 3 categories: never, past and current smoking. Consumption of alcohol was categorised as yes/no. BMI was calculated as weight $(\mathrm{kg})$ divided by height $(\mathrm{m})$ squared. Both weight and height were self-reported. The definition of obesity was BMI $\geq 30 \mathrm{~kg} / \mathrm{m}^{2}$. In relation to the presence of other comorbidities, participants were divided in two groups: those who had one or more comorbidities and those who had no comorbidities. Medication intake was considered as a dichotomous variable as well. Participants were included in the "yes" group if they had taken at least one of the following twenty-two medications in the last two weeks: (1) flu/cold medication; (2) pain medication; (3) fever medication; (4) sedatives; (5) allergy medication; (6) antibiotics; (7) diarrhoea medication; (8) heart medication; (9) rheumatism medication; (10) blood pressure medication; (11) digestive problems medication; (12) diabetes medication; (13) antidepressants; (14) laxatives; (15) vitamins/minerals/tonics; (16) slimming medicines; (17) cholesterol medication; (18) thyroid medication; (19) menopausal hormones; (20) contraceptive pill; (21) natural products (plant-based products [31]); (22) others.

\subsection{Data Analyses}

The characteristics of the sample were described through descriptive statistics. The mean and SD (standard deviation) were used for continuous variables (age, BMI), while frequencies and percentages were utilized for categorical variables (sex, age, marital status, education level, smoking, alcohol consumption, obesity, medication intake, presence of comorbidities and PA). Descriptive statistics were used to determine the prevalence of every comorbidity and group of comorbidities as well. Statistical significance in sample characteristics according to PA was analysed by chi-squared tests (categorical variables) and $\mathrm{T}$ test (continuous variables)

Multivariable logistic regression analyses were employed to study the associations between each comorbidity and quantity of PA. Three different models were used to carry out the analyses. Model 1 was not adjusted; Model 2 was adjusted for sex, age, BMI education level, marital status, smoking habits and alcohol consumption; and Model 3 was adjusted considering the variables "presence of other comorbidities" and "medication intake" as well, in addition to the same variables used in Model 2. All variables were included in the regression analyses as categorical variables except age and BMI, which were treated as continuous variables. There were missing data only on the variable BMI $(2.2 \%)$. Results from the multivariable logistic regression analyses were presented as odds ratios (OR) with $95 \%$ of confidence intervals (CI). Bonferroni correction was applied to control the family-wise error rate, so statistical significance was set at $p<0.0016$.

Statistical Package for Social Sciences version 23 (SPSS, International Business Machines Corporation, Armonk, NY, USA) was used to carry out these analyses.

\section{Results}

The sample was composed of 1014 Spanish asthmatic people. Participants' mean age (SD) was 43.17 (14.7) years, with a range between $15-69$ years. A total of $57.9 \%$ were females, and $42.1 \%$ were males. The prevalence of participants who do not reach PA recommendations was $31.6 \%$. Nine out of ten people with asthma presented comorbidities. An average of 3.6 concurrent comorbidities (max:20, min:3, mo:1) was found. In Table 1, sample characteristics are described according to PA level.

The differences in sample characteristics according to PA were significant for education level, marital status, alcohol consumption, obesity, BMI and age.

Overall, the prevalence of comorbidities in asthmatics is shown in Table 2. Chronic allergy showed the highest prevalence, with $61.1 \%$. Chronic lumbar and cervical pain, high cholesterol, COPD, migraine and hypertension were diseases with a high prevalence as well, all of them with around a 30-20\% prevalence. According to the ICD classification, sixty-one-point-pone percent of asthma participants had immunological disease, followed by musculoskeletal disorders (39.1\%), cardiovascular diseases (32.2\%) and endocrinal and metabolic diseases (27.3\%). 
Associations between asthma comorbidities and PA are shown in Table 3. When models were not adjusted, hypertension, arthrosis, chronic cervical and lumbar pain, osteoporosis, chronic constipation, haemorrhoids, urinary incontinence, kidney problems, cataracts, depression, chronic anxiety and migraine were significantly associated with PA $(p<0.05)$. When models were adjusted for age, BMI, sex, education level, marital status, smoking and alcohol consumption, engaging in less than $600 \mathrm{MET} \cdot \mathrm{min} /$ week of PA was significantly associated with a greater probability of existing osteoporosis, urinary incontinence and chronic anxiety $(p<0.05)$. When the analyses were adjusted for medication intake and presence of comorbidities as well, PA was also significantly associated with osteoporosis, urinary incontinence and chronic anxiety $(p<0.05)$. Urinary incontinence showed the highest probability with an odds ratio of 3.10 [1.62-5.94]. Nevertheless, when Bonferroni correction was applied, only chronic anxiety, depression, urinary incontinence, osteoporosis and arthrosis were significant (unadjusted models) and urinary incontinence when models were adjusted $(p<0.001)$. 
Table 3. Association of PA and asthma comorbidities (outcome) estimated by multivariable logistic regression.

\begin{tabular}{|c|c|c|c|c|c|c|c|c|c|}
\hline Comorbidities & $\mathrm{OR}^{1}$ & CI $95 \%{ }^{1}$ & $p^{1}$ & $\mathrm{OR}^{2}$ & CI $95 \%^{2}$ & $p^{2}$ & $\mathrm{OR}^{3}$ & CI $95 \%^{3}$ & $p^{3}$ \\
\hline Hypertension & 1.49 & $1.08-2.06$ & $0.016^{*}$ & 1.11 & $0.76-1.61$ & 0.592 & 1.10 & $0.75-1.62$ & 0.616 \\
\hline Myocardial infarction & 0.87 & $0.27-2.78$ & 0.809 & 0.26 & $0.06-1.14$ & 0.074 & 0.52 & $0.06-1.13$ & 0.071 \\
\hline Angina, coronary HD & 1.08 & $0.74-4.38$ & 0.197 & 0.83 & $0.29-2.38$ & 0.734 & 0.83 & $0.28-2.40$ & 0.723 \\
\hline Other HD & 1.23 & $0.62-2.23$ & 0.489 & 1.08 & $0.58-2.02$ & 0.796 & 1.08 & $0.58-2.02$ & 0.805 \\
\hline Stroke & 2.20 & $0.82-5.91$ & 0.118 & 1.31 & $0.45-3.84$ & 0.625 & 1.26 & $0.43-3.74$ & 0.672 \\
\hline Varicose veins (legs) & 1.15 & $0.79-1.68$ & 0.452 & 0.85 & $0.56-1.28$ & 0.437 & 0.85 & $0.56-1.28$ & 0.435 \\
\hline Arthrosis & 1.93 & $1.40-2.68$ & $<0.001 * *$ & 1.39 & $0.93-2.07$ & 0.109 & 1.37 & $0.91-2.06$ & 0.130 \\
\hline CBP cervical & 1.46 & $1.08-1.97$ & $0.014 *$ & 1.20 & $0.86-1.67$ & 0.289 & 1.20 & $0.86-1.69$ & 0.282 \\
\hline CBP lumbar & 1.52 & $1.14-2.02$ & $0.004 *$ & 1.31 & $0.96-1.78$ & 0.089 & 1.32 & $0.96-1.80$ & 0.087 \\
\hline Osteoporosis & 2.58 & $1.45-4.60$ & $0.001 * *$ & 1.96 & $1.04-3.70$ & $0.036^{*}$ & 1.90 & $1.00-3.61$ & $0.048^{*}$ \\
\hline Chronic allergy & 0.90 & $0.69-1.19$ & 0.467 & 0.91 & $0.68-1.21$ & 0.495 & 0.83 & $0.60-1.14$ & 0.253 \\
\hline COPD & 1.29 & $0.927-1.78$ & 0.132 & 1.02 & $0.72-1.46$ & 0.899 & 1.01 & $0.70-1.44$ & 0.979 \\
\hline Liver dysfunction & 1.98 & $0.80-4.92$ & 0.142 & 1.40 & $0.54-3.64$ & 0.486 & 1.36 & $0.52-3.54$ & 0.536 \\
\hline Stomach/duodenal ulcer & 1.48 & $0.85-2.58$ & 0.168 & 1.00 & $0.54-1.84$ & 0.995 & 1.01 & $0.54-1.86$ & 0.986 \\
\hline Chronic constipation & 2.01 & $1.21-3.34$ & $0.007^{*}$ & 1.56 & $0.90-2.68$ & 0.112 & 1.56 & $0.90-2.69$ & 0.115 \\
\hline Haemorrhoids & 1.57 & $1.06-2.33$ & $0.024 *$ & 1.31 & $0.86-2.00$ & 0.207 & 1.33 & $0.87-2.03$ & 0.196 \\
\hline Urinary incontinence & 4.32 & $2.39-7.80$ & $<0.001^{* *}$ & 3.22 & $1.69-6.15$ & $<0.001 * *$ & 3.10 & $1.62-5.94$ & $0.001 * *$ \\
\hline Kidney problems & 1.96 & $1.14-3.37$ & $0.015 *$ & 1.42 & $0.80-2.54$ & 0.236 & 1.39 & $0.78-2.50$ & 0.265 \\
\hline Prostate problems (males) & 1.51 & $0.67-3.40$ & 0.317 & 0.89 & $0.33-2.41$ & 0.821 & 0.88 & $0.31-2.48$ & 0.813 \\
\hline Menopausal problems (females) & 0.98 & $0.55-1.75$ & 0.947 & 0.82 & $0.43-1.54$ & 0.532 & 0.82 & $0.43-1.56$ & 0.535 \\
\hline Cataracts & 1.97 & $1.16-3.36$ & $0.013 *$ & 1.43 & $0.76-2.68$ & 0.270 & 1.41 & $0.75-2.65$ & 0.292 \\
\hline Chronic skin problems & 1.18 & $0.77-1.77$ & 0.428 & 1.15 & $0.76-1.74$ & 0.511 & 1.15 & $0.75-1.75$ & 0.517 \\
\hline Depression & 1.84 & $1.29-2.61$ & $0.001 * *$ & 1.37 & $0.92-2.04$ & 0.126 & 1.33 & $0.89-1.99$ & 0.168 \\
\hline Chronic anxiety & 2.15 & $1.50-3.09$ & $<0.001 * *$ & 1.72 & $1.16-2.56$ & $0.007^{*}$ & 1.69 & $1.13-2.53$ & $0.010 *$ \\
\hline Other mental problems & 1.21 & $0.55-2.66$ & 0.632 & 0.93 & $0.40-2.15$ & 0.866 & 0.89 & $0.39-2.06$ & 0.787 \\
\hline Migraine & 1.39 & $1.00-1.92$ & $0.050 *$ & 1.21 & $0.86-1.72$ & 0.276 & 1.23 & $0.86-1.76$ & 0.260 \\
\hline Malignant tumours & 1.56 & $0.88-2.76$ & 0.132 & 1.44 & $0.78-2.64$ & 0.240 & 1.41 & $0.77-2.59$ & 0.272 \\
\hline Thyroid problems & 1.18 & $0.74-1.89$ & 0.489 & 1.03 & $0.62-1.70$ & 0.910 & 1.03 & $0.62-1.70$ & 0.923 \\
\hline Diabetes & 1.38 & $0.85-2.26$ & 0.196 & 0.86 & $0.49-1.51$ & 0.602 & 0.82 & $0.47-1.45$ & 0.497 \\
\hline High cholesterol & 1.18 & $0.86-1.63$ & 0.311 & 0.90 & $0.62-1.30$ & 0.572 & 0.88 & $0.61-1.28$ & 0.505 \\
\hline Permanent injuries (accident) & 1.00 & $0.63-1.58$ & 0.994 & 0.86 & $0.53-1.39$ & 0.535 & 0.84 & $0.52-1.37$ & 0.489 \\
\hline
\end{tabular}

HD: heart disease. CBP: chronic back pain. OR: odds ratio. CI: confidence interval. ${ }^{*} p<0.05 .{ }^{* *} p<0.001 .{ }^{1}$ Models not adjusted. ${ }^{2}$ Models adjusted for sex, age, BMI, education level, marital status, smoking and alcohol consumption. ${ }^{3}$ Models adjusted for sex, age, BMI, education level, marital status, smoking, alcohol consumption, medication intake and presence of comorbidities. 


\section{Discussion}

To the best of authors' knowledge, the present study was the first study carried out in Spain analysing in a representative sample the associations between PA and the presence of 31 different asthma comorbidities. The results of the present study showed that not achieving PA recommendations was associated with more risk of comorbidities, especially urinary incontinence, osteoporosis and chronic anxiety.

The presence of comorbidities was high among Spanish with asthma aged 15-69 years. A total of $87.3 \%$ of the participants presented at least one comorbidity. It was higher than the prevalence of comorbidities found in another cross-sectional research among 84,505 Scottish adults with asthma that showed a $62.6 \%$ prevalence of asthmatics with one or more health conditions [26]. The most prevalent comorbidity was chronic allergy $(61.1 \%)$, likely owing to many asthma patients having a phenotype of allergic asthma, which is associated with past and/or a family history of allergic diseases [1]. This concurred with previous studies that have also found allergic conditions like sinusitis, rhinitis, dermatitis, eczema and food allergy as important asthma comorbidities [39,40]. Allergy could be connected to asthma through genetic and environmental factors, which predispose people to contract this disease [25]. However, it is important to underline that our study did not find significant associations between low PA levels and existing chronic allergy among those with asthma $(p=0.467)$.

Chronic lumbar and cervical pain, high cholesterol, COPD, migraine and hypertension showed a high prevalence as well (20-30\%) among the participants of the present study. In another study, which analysed the prevalence of comorbidities in asthmatics adults, hypertension (20\%), depression $(17 \%)$, pain $(16 \%)$ and COPD $(13 \%)$, showed the highest prevalences [26]. Some of them concurred with our results, but they were slightly lower than in the current study. In a cohort study with a five year follow-up that compared the risk of comorbidities between individuals with and without asthma by age, a significantly higher physician claim among individuals with asthma aged 18-64 years for the vast majority of comorbidities was found, with $50 \%$ or more for respiratory diseases (without including asthma) and psychiatric conditions [25].

Several studies found that cardiovascular diseases [41,42] and metabolic diseases, like diabetes [43], decrease when patients engage in moderate-vigorous PA, but in this research, a significant correlation of these comorbidities in asthmatics who achieved PA recommendations (600 or more MET.min/week) was not found, with the exception of hypertension (OR $=1.49$; CI 95\% $=1.08-2.06$ ), when models were not adjusted.

In the current study, multivariable logistic regression showed that exercising less than $600 \mathrm{MET} \cdot \mathrm{min} /$ week was significantly associated with $210 \%$ higher odds of urinary incontinence, $90 \%$ of osteoporosis and $69 \%$ of chronic anxiety. When compared with healthy population, the odds for developing the previous comorbidities in asthmatics was high [44-47]. A longitudinal study carried out in older women concluded that performing less than 372 MET.min/week was associated with $4 \%$ higher odds for urinary incontinence $(\mathrm{OR}=1.04 \mathrm{CI} 95 \%=0.92-1.18)$. Recently, in a population study carried out in 124,434 healthy adults of South Korea, it was found that participants achieving 600-6000 MET.min/week had significantly lower risk of anxiety symptoms [44]. That barely concurred with the results of the present study, where we found a significant positive association between chronic anxiety and engaging in less than $600 \mathrm{MET} \cdot \mathrm{min} /$ week of PA in asthmatics. In this way, a recent meta-analysis concluded that higher levels of PA are correlated with a lower probability of developing anxiety [45]. An explanation of this could be the fact that engaging in PA helps them to avoid things they are anxious about, like thoughts relating to their condition. In relation to osteoporosis, Shetty et al. [46] reported a $40 \%$ lower risk of osteoporosis among active males and Shenoy et al. [47] found a $32 \%$ reduced osteoporosis risk with each extra 10 METs of PA. This barely concurred with our results, which reported a higher risk of osteoporosis in asthmatics who engaged in lower PA levels, but with higher odds $(100.2 \%)$.

Regarding cataracts, a newly published research work determined that exercising less than $600 \mathrm{MET}$-minutes/week was associated with a 32.3\% higher risk of cataracts [28]. The present study 
showed increased odds of cataracts in asthmatics as well, but it was much higher (97.1\%). However, the odds were only significant when models were not adjusted.

Recently, Sánchez-Castillo et al. [48] studied Spanish adults with COPD using data from the Spanish National Health Survey as well. When models were adjusted, this study showed significant increased odds for urinary incontinence $(110.6 \%)$, chronic constipation $(97.2 \%)$, cataracts $(82.5 \%)$, chronic anxiety $(50.8 \%)$ and chronic lumbar pain (48.7\%) in those who performed less than $600 \mathrm{MET} \cdot \mathrm{min} /$ week. Increased odds for urinary incontinence $(231.3 \%)$ and chronic anxiety $(70.6 \%)$ were also found in asthmatics. On the contrary, associations between PA and osteoporosis were reported, and significant associations with chronic constipation, chronic lumbar pain and cataracts in the adjusted models were not found. Currently, with the available literature, it is difficult to explain why different associations between PA and comorbidities among asthmatics and COPD patients appear. Randomized control trials are needed to clarify this.

When focusing on the long-term benefits of PA in asthmatics, Russell et al. [37] found a protective effect by increasing the frequency of low PA, but no significant associations were found with moderate and vigorous PA. Another recent longitudinal study determined that an exercise training program, together with a weight loss lifestyle in obese adults with asthma was able to reduce depression symptoms, asthma symptoms and the risk of obstructive sleep apnoea [49]. The present study found a significant positive correlation between comorbidities (chronic anxiety, urinary incontinence and osteoporosis) and undertaking a low quantity of PA, but long-term benefits could not be established because its cross-sectional character only allowed speculating about the direction of the association. In the contrary, Cassim et al. [50] found no association with PA on asthma nor asthma on PA. However, these associations were analysed in children and adolescents aged 6-14 years, so this comparison should be considered with caution.

The strengths of the current manuscript were its large representative sample of Spanish asthmatic people aged 15-69 years and the administration of an internationally recognized, validated and reliable questionnaire to assess PA. However, some limitations should be considered. IPAQ is a reference instrument in measuring a population's PA level, but it is self-reported, and people may over- or under-report their level of PA. Assessment of asthma and comorbidities was self-reported as well, thus potentially introducing bias into the analyses. Asthma subtype was not established because it was not specified in the Spanish National Health Survey. The question relating to asthma included all types of asthma (allergic, not allergic, adult-onset, asthma with persistent airflow limitation, asthma with obesity). Furthermore, due to the cross-sectional design, the direction of the associations found was unknown. Consequently, future longitudinal research is required to make this direction clearer.

\section{Conclusions}

Summarizing, nine out of ten people aged 15-69 years with asthma residing in Spain had comorbidities. Chronic allergy was the most prevalent with $61.1 \%$, followed by chronic lumbar and cervical pain, high cholesterol, COPD, migraine and hypertension. Unadjusted models determined significant positive associations between low PA (<600MET.min/week) and urinary incontinence, osteoporosis, chronic anxiety, arthrosis, depression, chronic back pain (CBP) lumbar, chronic constipation, cataracts, CBP cervical, kidney problems, hypertension, haemorrhoids and migraine. When adjusted by sex, age, BMI, education, marital status, smoking, alcohol, presence of comorbidities and medication intake, there was a significant association between low PA and existing urinary incontinence, osteoporosis and chronic anxiety among asthmatics. Therefore, comorbidities and PA levels should be considered in the prevention and treatment of asthmatics, in order to improve their quality of life.

Author Contributions: Writing, original draft preparation, S.S.C.; writing, review and editing, S.S.C., L.S., A.D.S., and G.F.L.S.; supervision, L.S., A.D.S., and G.F.L.S. All authors have read and agreed to the published version of the manuscript. 
Funding: This research was funded by the Seneca Foundation-Agency for Science and Technology of the Region of Murcia, Spain (20773/FPI/18).

Conflicts of Interest: The authors declare no conflict of interest. The funders had no role in the design of the study; in the collection, analyses, or interpretation of data; in the writing of the manuscript; nor in the decision to publish the results.

\section{References}

1. Global Initiative for Asthma. Global Strategy for Asthma Management and Prevention. 2020. Available online: www.ginasthma.org (accessed on 8 June 2020).

2. World Health Organization. Asthma. 2020. Available online: https://www.who.int/news-room/q-a-detail/ asthma (accessed on 8 June 2020).

3. To, T.; Stanojevic, S.; Moores, G.; Gershon, A.S.; Bateman, E.D.; Cruz, A.A.; Boulet, L.P. Global asthma prevalence in adults: Findings from the cross-sectional world health survey. BMC Public Health 2012, 12, 204. [CrossRef] [PubMed]

4. Sobradillo, V.; Miravitlles, M.; Jiménez, C.A.; Gabriel, R.; Viejo, J.L.; Masa, J.F.; Fernández-Fau, L.; Villasante, C. Estudio IBERPOC en España: Prevalencia de síntomas respiratorios habituales y de limitación crónica al flujo aéreo. Arch. Bronconeumol. 2015, 35, 159-166. [CrossRef]

5. Ministerio de Sanidad Consumo y Bienestar Social. Encuesta Nacional de Salud de España 2017. Available online: https://www.mscbs.gob.es/estadEstudios/estadisticas/encuestaNacional/encuesta2017.htm (accessed on 24 February 2020).

6. Cordova-Rivera, L.; Gibson, P.G.; Gardiner, P.A.; McDonald, V.M. A Systematic Review of Associations of Physical Activity and Sedentary Time with Asthma Outcomes. J. Allergy Clin. Immunol. Pract. 2018, 6, 1968-1981.e2. [CrossRef] [PubMed]

7. van't Hul, A.J.; Frouws, S.; Van Den Akker, E.; Van Lummel, R.; Starrenburg-Razenberg, A.; van Bruggen, A.; Braunstahl, G.J.; in't Veen, J.C. Decreased physical activity in adults with bronchial asthma. Respir. Med. 2016, 114, 72-77. [CrossRef]

8. Freitas, P.D.; Xavier, R.F.; Passos, N.F.; Carvalho-Pinto, R.M.; Cukier, A.; Martins, M.A.; Cavalheri, V.; Hill, K.; Stelmach, R.; Carvalho, C.R. Effects of a behaviour change intervention aimed at increasing physical activity on clinical control of adults with asthma: Study protocol for a randomised controlled trial. BMC Sports Sci. Med. Rehabil. 2019, 11, 16. [CrossRef]

9. Côté, A.; Turmel, J.; Boulet, L.P. Exercise and Asthma. Semin. Respir. Crit. Care Med. 2018, 39, 19-28. [CrossRef]

10. Yawn, B.P.; Rank, M.A.; Bertram, S.L.; Wollan, P.C. Obesity, low levels of physical activity and smoking present opportunities for primary care asthma interventions: An analysis of baseline data from The Asthma Tools Study. Prim. Care Respir. Med. 2015, 25, 15058. [CrossRef]

11. Turner, S.; Eastwood, P.; Cook, A.; Jenkins, S. Improvements in symptoms and quality of life following exercise training in older adults with moderate/severe persistent asthma. Respiration 2011, 81, 302-310. [CrossRef]

12. Loponen, J.; Ilmarinen, P.; Tuomisto, L.E.; Niemelä, O.; Tommola, M.; Nieminen, P.; Lehtimäki, L.; Kankaanranta, H. Daily physical activity and lung function decline in adult-onset asthma: A 12-year follow-up study. Respir. J. 2018, 5, 1533753. [CrossRef]

13. França-Pinto, A.; Mendes, F.A.; de Carvalho-Pinto, R.M.; Agondi, R.C.; Cukier, A.; Stelmach, R.; Saraiva-Romanholo, B.M.; Kalil, J.; Martins, M.A.; Giavina-Bianchi, P.; et al. Aerobic training decreases bronchial hyperresponsiveness and systemic inflammation in patients with moderate or severe asthma: A randomised controlled trial. Thorax 2015, 70, 732-739. [CrossRef] [PubMed]

14. Garcia-Aymerich, J.; Varraso, R.; Antó, J.M.; Camargo, C.A. Prospective study of physical activity and risk of asthma exacerbations in older women. Am. J. Respir. Crit. Care Med. 2009, 179, 999-1003. [CrossRef]

15. Carson, K.V.; Chandratilleke, M.G.; Picot, J.; Brinn, M.P.; Esterman, A.J.; Smith, B.J. Physical training for asthma. Cochrane Database Syst. Rev. 2013, 9, CD001116. [CrossRef] [PubMed]

16. Eichenberger, P.A.; Diener, S.N.; Kofmehl, R.; Spengler, C.M. Effects of exercise training on airway hyperreactivity in asthma: A systematic review and meta-analysis. Sport Med. 2013, 43, 1157-1170. [CrossRef] 
17. Feinstein, A.R. The pre-therapeutic classification of co-morbidity in chronic disease. J. Chronic Dis. 1970, 23, 455-468. [CrossRef]

18. Ledford, D.K.; Lockey, R.F. Asthma and comorbidities. Curr. Opin. Allergy Clin. Immunol. 2013, 13, 78-86. [CrossRef] [PubMed]

19. Boulet, L.P. Influence of comorbid conditions on asthma. Eur. Respir. J. 2009, 33, 897-906. [CrossRef] [PubMed]

20. Zhang, T.; Carleton, B.C.; Prosser, R.J.; Smith, A.M. The added burden of comorbidity in patients with asthma. J. Asthma 2009, 46, 1021-1026. [CrossRef]

21. Steppuhn, H.; Langen, U.; Keil, T.; Scheidt-Nave, C. Chronic disease co-morbidity of asthma and unscheduled asthma care among adults: Results of the national telephone health interview survey German Health Update (GEDA) 2009 and 2010. Prim. Care Respir. J. 2014, 23, 22-29. [CrossRef]

22. To, T.; Simatovic, J.; Zhu, J.; Feldman, L.; Dell, S.D.; Lougheed, M.D.; Licskai, C.; Gershon, A. Asthma Deaths in a Large Provincial Health System A 10-Year Population-Based Study. Ann. Am. Thorac. Soc. 2014, 11, 1210-1217. [CrossRef]

23. Ceylan, E.; Bulut, S.; Yılmaz, M.; Örün, H.; Karadă̆, F.; Ömürlü, İ.K.; Kırdar, S.; Karul, A. The levels of serum biomarkers in stable asthma patients with comorbidities. Iran. J. Allergy Asthma Immunol. 2019, 18, $27-37$. [CrossRef]

24. Su, X.; Ren, Y.; Li, M.; Zhao, X.; Kong, L.; Kang, J. Prevalence of comorbidities in asthma and non-asthma patients. Medicine 2016, 95, e3459. [CrossRef]

25. Gershon, A.S.; Guan, J.; Wang, C.; Victor, J.C.; To, T. Describing and Quantifying Asthma Comorbidty: A Population Study. PLoS ONE 2012, 7, e34967. [CrossRef]

26. Weatherburn, C.J.; Guthrie, B.; Mercer, S.W.; Morales, D.R. Comorbidities in adults with asthma: Population-based cross-sectional analysis of 1.4 million adults in Scotland. Clin. Exp. Allergy 2017, 47, 1246-1252. [CrossRef]

27. Warburton, D.E.R.; Nicol, C.W.; Bredin, S.S.D. Health benefits of physical activity: The evidence. CMAJ 2006, 174, 801-809. [CrossRef]

28. López-Sánchez, G.F.; Pardhan, S.; Trott, M.; Sánchez-Castillo, S.; Jackson, S.E.; Tully, M.; Gorely, T.; López-Bueno, R.; Veronese, N.; Skalska, M.; et al. The Association Between Physical Activity and Cataracts Among 17, 777 People Aged 15-69 Years Residing in Spain. Ophthalmic Epidemiol. 2020, 1-6. [CrossRef]

29. Haskell, W.L.; Lee, I.M.; Pate, R.R.; Powell, K.E.; Blair, S.N.; Franklin, B.A.; Macera, C.A.; Heath, G.W.; Thompson, P.D.; Bauman, A. Physical Activity and Public Health: Updated Recommendation for Adults from the American College of Sports Medicine and the American Heart Association. Circulation 2007, 116, 1081-1093. [CrossRef]

30. STROBE Group. STROBE Statement: Home. Available online: https://www.strobe-statement.org/index.php? id=strobe-home (accessed on 22 February 2020).

31. Ministerio de Sanidad Servicios Sociales e Igualdad, Instituto Nacional de Estadística. Encuesta Nacional de Salud 2017 Metodología. Available online: https://www.mscbs.gob.es/estadEstudios/estadisticas/ encuestaNacional/encuestaNac2017/ENSE17_Metodologia.pdf (accessed on 5 February 2020).

32. IPAQ Group. Guidelines for Data Processing and Analysis of the International Physical Activity Questionnaire (IPAQ). Available online: https://sites.google.com/site/theipaq/scoring-protocol (accessed on 2 February 2020).

33. Craig, C.L.; Marshall, A.L.; Sjöström, M.; Bauman, A.E.; Booth, M.L.; Ainsworth, B.E.; Pratt, M.; Ekelund, U.L.; Yngve, A.; Sallis, J.F.; et al. International Physical Activity Questionnaire: 12-Country Reliability and Validity. Med. Sci. Sport Exerc. 2003, 35, 1381-1395. [CrossRef]

34. Roman-Viñas, B.; Serra-Majem, L.; Hagströmer, M.; Ribas-Barba, L.; Sjöström, M.; Segura-Cardona, R. International physical activity questionnaire: Reliability and validity in a Spanish population. Eur. J. Sport Sci. 2010, 10, 297-304. [CrossRef]

35. ICD-11-Mortality and Morbidity Statistics. Available online: https://icd.who.int/browse11/l-m/en (accessed on 7 February 2020).

36. Brumpton, B.M.; Langhammer, A.; Ferreira, M.A.R.; Chen, Y.; Mai, X.M. Physical activity and incident asthma in adults: The HUNT Study, Normay. BMJ Open 2016, 6. [CrossRef] [PubMed]

37. Russell, M.A.; Janson, C.; Real, F.G.; Johannessen, A.; Waatevik, M.; Benediktsdóttir, B.; Holm, M.; Lindberg, E.; Schlünssen, V.; Raza, W.; et al. Physical activity and asthma: A longitudinal and multi-country study. J. Asthma 2017. [CrossRef] 
38. Instituto Nacional de Estadística. Clasificación Nacional de Educación 2014 (CNED-2014). Available online: https:/www.ine.es/daco/daco42/clasificaciones/cned14/CNED2014_capitulo0.pdf (accessed on 15 February 2020).

39. Liu, A.H.; Jaramillo, R.; Sicherer, S.H.; Wood, R.A.; Bock, S.A.; Burks, A.W.; Massing, M.; Cohn, R.D.; Zeldin, D.C. National prevalence and risk factors for food allergy and relationship to asthma: Results from the National Health and Nutrition Examination Survey 2005-2006. J. Allergy Clin. Immunol. 2010, 126, 798-806.e13. [CrossRef] [PubMed]

40. Bousquet, J.; Schünemann, H.J.; Samolinski, B.; Demoly, P.; Baena-Cagnani, C.E.; Bachert, C.; Bonini, S.; Boulet, L.P.; Bousquet, P.J.; Brozek, J.L.; et al. Allergic Rhinitis and its Impact on Asthma (ARIA): Achievements in 10 years and future needs. J. Allergy Clin. Immunol. 2012, 130, 1049-1062. [CrossRef] [PubMed]

41. Liu, Q.; Liu, F.C.; Huang, K.Y.; Li, J.X.; Yang, X.L.; Wang, X.Y.; Chen, J.C.; Liu, X.Q.; Cao, J.; Shen, C.; et al. Beneficial effects of moderate to vigorous physical activity on cardiovascular disease among Chinese adults. J. Geriatr. Cardiol. 2020, 17, 85-95. [CrossRef]

42. Kraus, W.E.; Powell, K.E.; Haskell, W.L.; Janz, K.F.; Campbell, W.W.; Jakicic, J.M.; Troiano, R.P.; Sprow, K.; Torres, A.; Piercy, K.L. Physical Activity, All-Cause and Cardiovascular Mortality, and Cardiovascular Disease. Med. Sci. Sport Exerc. 2019, 51, 1270-1281. [CrossRef]

43. Yerramalla, M.S.; Fayosse, A.; Dugravot, A.; Tabak, A.G.; Kivimäki, M.; Singh-Manoux, A.; Sabia, S. Association of moderate and vigorous physical activity with incidence of type 2 diabetes and subsequent mortality: 27 year follow-up of the Whitehall II study. Diabetologia 2020, 63, 537-548. [CrossRef] [PubMed]

44. Kim, S.Y.; Jeon, S.W.; Lee, M.Y.; Shin, D.W.; Lim, W.J.; Shin, Y.C.; Oh, K.S. The association between physical activity and anxiety symptoms for general adult populations: An analysis of the dose-response relationship. Psychiatry Investig. 2020, 17, 29-36. [CrossRef]

45. Schuch, F.B.; Stubbs, B.; Meyer, J.; Heissel, A.; Zech, P.; Vancampfort, D.; Rosenbaum, S.; Deenik, J.; Firth, J.; Ward, P.B.; et al. Physical activity protects from incident axiety: A meta-analysis of prospective cohort studies. Depress. Anxiety 2019, 36, 846-858. [CrossRef]

46. Shetty, S.; Kapoor, N.; Naik, D.; Asha, H.S.; Prabu, S.; Thomas, N.; Seshadri, M.S.; Paul, T.V. Osteoporosis in healthy south Indian males and the influence of life style factors and vitamin D status on bone mineral density. J. Osteoporos. 2014, 2014. [CrossRef]

47. Shenoy, S.; Chawla, J.K.; Gupta, S.; Sandhu, J.S. Prevalence of low bone health using quantitative ultrasound in Indian women aged 41-60 years: Its association with nutrition and other related risk factors. J. Women Aging 2017, 29, 334-347. [CrossRef]

48. Sánchez-Castillo, S.; Smith, L.; Díaz-Suárez, A.; López-Sánchez, G.F. Associations between physical activity and comorbidities in people with COPD residing in Spain: A cross-sectional analysis. Int. J. Environ. Res. Public Health 2020, 17, 594. [CrossRef]

49. Freitas, P.D.; Silva, A.G.; Ferreira, P.G.; Da Silva, A.; Salge, J.M.; Carvalho-Pinto, R.M.; Cukier, A.; Brito, C.M.; Mancini, M.C.; Carvalho, C.R. Exercise Improves Physical Activity and Comorbidities in Obese Adults with Asthma. Med. Sci. Sports Exerc. 2018, 50, 1367-1376. [CrossRef]

50. Cassim, R.; Milanzi, E.; Koplin, J.J.; Dharmage, S.C.; Russel, M.A. Physical activity and asthma: Cause or consequence? A bidirectional longitudinal analysis. J. Epidemiol. Commun. H 2018, 79, 770-775. [CrossRef]

(C) 2020 by the authors. Licensee MDPI, Basel, Switzerland. This article is an open access article distributed under the terms and conditions of the Creative Commons Attribution (CC BY) license (http://creativecommons.org/licenses/by/4.0/). 